\title{
Acute and Long-Term Outcomes of Patients with Impaired Left Ventricular Systolic Function Undergoing Rotational Atherectomy: A Single-Center Observational Retrospective Study
}

\author{
Nader Mankerious - Rayyan Hemetsberger - Ralph Toelg • \\ Mohamed Abdel-Wahab · Gert Richardt · Abdelhakim Allali
}

Received: June 20, 2019 / Published online: July 27, 2019

(c) The Author(s) 2019

\begin{abstract}
Introduction: Rotational atherectomy (RA) historically was contraindicated in patients with impaired left ventricular (LV) function due to inherent cardio-depressive effects. Contemporary RA practice is less aggressive than traditional RA and no longer withheld from patients with reduced ejection fraction (EF). The aim of this analysis is to explore the outcomes of rotational atherectomy (RA) in patients with reduced left ventricular ejection fraction (LVEF). Methods: Patients undergoing RA $(n=644)$ were divided into three groups according to LVEF $\quad$ (severely $\quad$ reduced $\leq 35 \%, \quad n=82$;
\end{abstract}

Enhanced Digital Features To view enhanced digital features for this article go to https://doi.org/10.6084/ m9.figshare.8910809.

Electronic supplementary material The online version of this article (https://doi.org/10.1007/s40119019-0143-4) contains supplementary material, which is available to authorized users.

N. Mankerious $(\varangle) \cdot$ R. Hemetsberger · R. Toelg · G. Richardt · A. Allali

The Heart Center, Segeberger Kliniken (Academic Teaching Hospital of the Universities of Kiel, Lübeck, and Hamburg), Bad Segeberg, Germany e-mail: nader.mankerious@gmail.com

M. Abdel-Wahab

Cardiology Department, Heart Center Leipzig,

University Hospital, Leipzig, Germany moderately reduced $36-54 \%, n=170$; and preserved LVEF $\geq 55 \%, n=392$ ).

Results: Compared to patients with preserved LVEF, those with severely reduced LVEF had higher rates of angiographic failure (12.2 vs. $3.3 \%, p=0.003)$ and in-hospital major adverse cardiac events (MACE: 9.8 vs. $2.3 \%, p=0.004$ ) driven by more peri-procedural myocardial infarction (MI: 6.1 vs. $1.5 \%, p=0.049$ ). In-hospital outcomes were similar between patients with preserved and moderately reduced LVEF. At 5-year follow-up, a stepwise increase in allcause death was observed with lower LVEF (preserved: $15 \%$, moderately reduced: 23\%, severely reduced: $43 \% ; p<0.001)$. On the other hand, revascularization and MI rates at 5 years were not affected by LVEF.

Conclusions: Compared to patients with preserved LVEF, those with severely reduced LVEF have worse acute outcomes after RA, whereas a moderate reduction of LVEF poses no additional acute hazard after RA. Up to 5 years, the extent of left ventricular dysfunction was associated with a stepwise increase in mortality.

Keywords: Coronary calcification; Ejection fraction; Rotational atherectomy

\section{INTRODUCTION}

The role of rotational atherectomy (RA) in contemporary percutaneous coronary 
interventions (PCI) is expanding, especially with extension of PCI to more challenging anatomical settings [1]. Severely calcified coronary lesions exist in $6-20 \%$ of PCI patients $[2,3]$. Calcification makes PCI more complex and increases the risk of complications such as stent under-expansion, restenosis, target lesion revascularization, myocardial infarction (MI), and death $[4,5]$. Another challenge for PCI arises from reduced left ventricular ejection fraction (LVEF), which has an adverse effect on acute and long-term outcomes [6, 7].

RA was historically not recommended in patients with impaired LV function due to inherent acute cardio-depressive effects [8]. Contemporary RA practice tends to modify calcified plaques by using smaller burrs and lower rotational speeds rather than aggressive debulking of the lesion. The modern approach is assumed to cause less vessel injury and microvascular obstruction [9] and could therefore be a safer strategy in patients with impaired LV function. Additionally, the expanding use of percutaneous mechanical circulatory support (PMCS) facilitates PCI in complex anatomies and unstable hemodynamic settings and/or impaired LV function [10].

The aim of this analysis is to investigate the outcomes of RA in patients with reduced LVEF.

\section{METHODS}

\section{Study Design and Patients}

This is a retrospective analysis of patients who underwent RA at a single tertiary center (Heart Centre, Segeberger Kliniken, Bad Segeberg, Germany) between November 2002 and February 2018. Written informed consent was obtained from all patients for analysis of their anonymized data, and data collection was approved by the local ethics committee (Segeberger Kliniken, Bad Segeberg, Germany). The study conforms with the Helsinki Declaration of 1964, as revised in 2013, concerning human and animal rights.

Out of 740 consecutive patients that underwent RA in that time period, 91 presenting with MI and five with no baseline LVEF measurement were excluded. The remaining patients were divided into three groups based on LVEF: severely reduced LVEF $\leq 35 \%$, moderately reduced LVEF $36-54 \%$, and preserved LVEF $\geq 55 \%$. The study flowchart is shown in Fig. 1. Echocardiography assessment was according to guidelines utilizing the biplane Simpson's method [11] and was confirmed by LV angiography. Clinical follow-up was obtained either by on-site clinical visit or scripted telephone interview with the patients or their general practitioners.

\section{Procedural Details and Medical Interventions}

RA was applied in severely calcified lesions according to the operator discretion as either primary or a bailout strategy in lesions that were uncrossable by balloons or stents. Technical details of RA at our institution have been previously reported $[9,12]$. Briefly, for all cases, RA was performed using the CE-marked Rotablator device (Boston Scientific Scimed Inc., Maple Grove, MN, USA). The burr size was selected

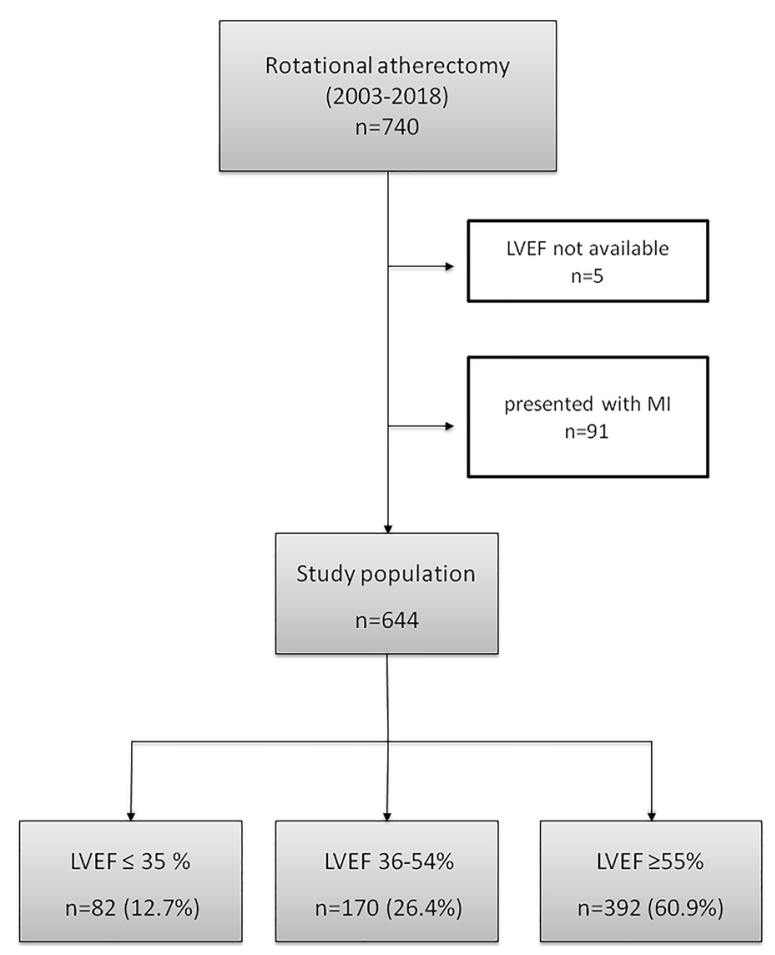

Fig. 1 Study flowchart. $M I$ myocardial infarction, $L V E F$ left ventricular ejection fraction 
aiming at a burr/vessel ratio of 0.5 (max. 0.7 if needed) and rotational speed was 140,000-180,000 rotations per minute (rpm). To prevent slow flow, a continuous intracoronary infusion of unfractionated heparin (UFH), nitroglycerine, and verapamil was used during RA. Prior to RA, patients were treated with 325-500 mg aspirin orally and an oral loading dose of a P2Y12 inhibitor (clopidogrel, prasugrel, or ticagrelor) and peri-procedural anticoagulation with either UFH or bivalirudin was routinely administered. The use of glycoprotein IIb/IIIa inhibitors and PMCS [e.g., with an intraaortic balloon pump or the Impella system (Abiomed Inc., Danvers, MA, USA)] was at the operator's discretion.

\section{Endpoint Definitions}

Angiographic failure was defined as residual stenosis of $\geq 30 \%$ and/or less than residual thrombolysis in myocardial infarction (TIMI) III flow at the end of the procedure. Spontaneous MI as well as peri-procedural MI were defined according to the third universal definition of MI [13]. Coronary dissection was defined as any dissection requiring additional stenting beyond the primary lesion. Target vessel revascularization (TVR) was defined as any repeated PCI or coronary bypass of the target vessel. Major adverse cardiac events (MACE) were defined as the composite endpoint of all-cause death, MI, and TVR.

\section{Statistical Analysis}

Qualitative variables are summarized as frequencies and percentages, while quantitative variables are summarized as mean \pm SD or median [25th-75th quartiles], depending on variable distribution. Inter-group comparisons were conducted using ANOVA test or Kruskal-Wallis test for continuous variables and by Chi-square test for categorical variables. Survival curves were created using the Kaplan-Meier method, and compared using log rank and Cox hazard regression analyses. For the latter, the hazard ratio (HR) and the 95\% confidence interval (CI) are presented.
Multivariable binary logistic regression analysis and multivariable Cox regression analysis were performed using entry criteria of $p<0.1$ in univariable analysis. Data analysis was performed using SPSS V.24.0 (IBM Corp., New York, NY, USA).

\section{RESULTS}

The mean age of the population was $72.3 \pm 8.6$ years, $75 \%$ were males, and LVEF was $52 \pm 13 \%$. LVEF was severely reduced in 82 patients $(12.7 \%)$, moderately reduced in 170 $(26.4 \%)$, and preserved in $392(60.9 \%)$. The average LVEF in the three groups was 28.9, 46.5, and $60.9 \%$, respectively.

\section{Demographic and Procedural Characteristics}

Patients with severely and moderately reduced LVEF were more likely to have three-vessel coronary artery disease $(p<0.001)$ with a higher prevalence of chronic renal impairment $(p<0.001)$, history of MI $(p<0.001)$, history of PCI $(p=0.043)$, and history of coronary artery bypass grafting (CABG, $p<0.001)$. Patients' characteristics are summarized in Table 1.

Target lesions within the reduced LVEF groups were more often ostial $(p=0.012)$, and patients more frequently received PMCS during PCI $(p<0.001)$. Lesion and procedural characteristics are shown in Table 2.

\section{Procedural Outcomes}

Patients with severely reduced LVEF had a higher rate of angiographic failure as compared to patients with preserved LVEF [12.2 vs. 3.3\%; odds ratio (OR): 4.05, 95\% confidence interval (CI) $1.71-9.59, p=0.001]$. This was driven by more frequent residual stenosis $\geq 30 \%$ (8.5 vs. 2\%; OR: $4.48,95 \%$ CI 1.58-12.73, $p=0.005$ ) and slow flow (11 vs. 2\%; OR: 5.92, 95\% CI 2.21-15.84, $p<0.001)$. On the other hand, patients with moderately reduced LVEF did not have an increased rates of angiographic failure as compared to patients with preserved LVEF 
Table 1 Patients and demographic characteristics

\begin{tabular}{|c|c|c|c|c|}
\hline & $\begin{array}{l}\text { LVEF } \leq 35 \%(n=82 \\
\text { patients })\end{array}$ & $\begin{array}{l}\text { LVEF } 36-54 \%(n=170 \\
\text { patients) }\end{array}$ & $\begin{array}{l}\text { LVEF } \geq 55 \%(n=392 \\
\text { patients })\end{array}$ & $p$ value \\
\hline Age, years & $72.5 \pm 8.7$ & $72.93 \pm 8.3$ & $71.9 \pm 8.4$ & 0.813 \\
\hline Male & $64(78.0 \%)$ & $128(75.3 \%)$ & $288(73.5 \%)$ & 0.664 \\
\hline BMI, $\mathrm{kg} / \mathrm{m}^{2}$ & $27.2 \pm 4.4$ & $27.9 \pm 5.0$ & $27.8 \pm 4.7$ & 0.546 \\
\hline LV. Ejection fraction \% & $28.9 \pm 5.8$ & $46.5 \pm 3.8$ & $60.9 \pm 4.4$ & $<0.001$ \\
\hline Clinical presentation & & & & 0.207 \\
\hline Chronic stable angina & $76(92.7 \%)$ & $144(84.7 \%)$ & $341(87.0 \%)$ & \\
\hline Unstable angina & $6(7.3 \%)$ & $26(15.3 \%)$ & $51(13 \%)$ & \\
\hline Number of diseased vessels & & & & $<0.001$ \\
\hline One & $7(8.5 \%)$ & $15(8.8 \%)$ & $77(19.6 \%)$ & \\
\hline Two & $19(23.2 \%)$ & $39(22.9 \%)$ & $124(31.6 \%)$ & \\
\hline Three & $56(68.3 \%)$ & $116(68.2 \%)$ & $191(48.7 \%)$ & \\
\hline Diabetes mellitus & $26(32.1 \%)$ & $64(37.6 \%)$ & $133(34.1 \%)$ & 0.620 \\
\hline Arterial hypertension & $73(90.1 \%)$ & $161(94.7 \%)$ & $349(89.5 \%)$ & 0.136 \\
\hline Dyslipidemia & $50(61.7 \%)$ & $119(70.1 \%)$ & $251(64.4 \%)$ & 0.323 \\
\hline Smoking & $27(33.3 \%)$ & $47(27.6 \%)$ & $127(32.6 \%)$ & 0.473 \\
\hline Familial history & $175(18.5 \%)$ & $33(19.4 \%)$ & $100(25.6 \%)$ & 0.159 \\
\hline $\begin{array}{l}\text { Chronic renal impairment } \\
\qquad(\text { GFR }<60)\end{array}$ & $19(32.2 \%)$ & $40(24.4 \%)$ & $42(11 \%)$ & $<0.001$ \\
\hline Previous MI & $27(32.9 \%)$ & $56(32.9 \%)$ & $50(12.8 \%)$ & $<0.001$ \\
\hline Previous PCI & $43(52.4 \%)$ & $68(40.0 \%)$ & $147(37.5 \%)$ & 0.043 \\
\hline Previous CABG & $327(32.9 \%)$ & $49(28.8 \%)$ & $57(14.5 \%)$ & $<0.001$ \\
\hline
\end{tabular}

Data are shown as number (percentage), mean \pm standard deviation

$B M I$ body mass index, $L V$ left ventricle, $M I$ myocardial infarction, $P C I$ percutaneous coronary intervention, $C A B G$ coronary artery bypass grafting

(6.5 vs. 3.3\%; OR: 2.02, 95\% CI 0.89-4.60, $p=0.10)$. Procedural outcomes are shown in Fig. 2.

On multivariate analysis, angiographic failure was associated with severely reduced LVEF group (OR: 3.36, 95\% CI 1.23-9.22, $p=0.018$ ) as well as CTO interventions (OR: 2.96, 95\% CI 1.04-8.46, $p=0.043$ (Table 3).

\section{In-Hospital MACE}

The rate of in-hospital MACE was 9.8, 3.5, and $2.3 \%$ in patients with $\mathrm{LVEF} \leq 35,36-54$, and $\geq 55 \%$, respectively $(p=0.004)$. Compared to patients with preserved LVEF, in-hospital MACE was significantly higher in patients with severely reduced LVEF (OR: 4.60, CI 1.72-12.31, $p=0.002)$ and the difference was driven by more peri-procedural MI (6.1 vs. 1.5\%; OR: 4.17, 
Table 2 Lesions and procedural characteristics

\begin{tabular}{|c|c|c|c|c|}
\hline & $\begin{array}{l}\text { LVEF } \leq 35 \% \\
(n=89 \text { lesions })\end{array}$ & $\begin{array}{l}\text { LVEF } 36-54 \% \\
(n=184 \text { lesions })\end{array}$ & $\begin{array}{l}\text { LVEF } \geq 55 \% \\
(n=421 \text { lesions })\end{array}$ & $p$ value \\
\hline \multicolumn{5}{|l|}{ Target vessel } \\
\hline Left main & $12(13.5 \%)$ & $30(16.3 \%)$ & $40(9.5 \%)$ & 0.051 \\
\hline Left anterior descending & $29(32.6 \%)$ & $74(40.2 \%)$ & $219(52.0 \%)$ & 0.001 \\
\hline Left circumflex & $18(20.2 \%)$ & $27(14.7 \%)$ & $43(10.2 \%)$ & 0.023 \\
\hline Right coronary artery & $30(33.7 \%)$ & $53(28.8 \%)$ & $119(28.3 \%)$ & 0.587 \\
\hline Ad hoc PCI & $10(11.2 \%)$ & $22(12.0 \%)$ & $59(14.0 \%)$ & 0.673 \\
\hline Chronic total occlusion & $9(10.1 \%)$ & $19(10.3 \%)$ & $23(5.5 \%)$ & 0.061 \\
\hline Bifurcation lesion & $33(37.1 \%)$ & $72(39.1 \%)$ & $168(39.9 \%)$ & 0.882 \\
\hline Ostial lesion & $28(31.5 \%)$ & $57(31 \%)$ & $89(21.1)$ & 0.012 \\
\hline ACC/AHA type B2/C* & $83(93.3 \%)$ & $162(88.0 \%)$ & $370(87.9 \%)$ & 0.366 \\
\hline Predilatation & $80(90.9 \%)$ & $163(88.6 \%)$ & $375(89.9)$ & 0.815 \\
\hline Burr sizes & & & & 0.188 \\
\hline 1.25 & $20(24.1 \%)$ & $47(26.1 \%)$ & $103(24.9 \%)$ & \\
\hline 1.5 & $46(52.9 \%)$ & $71(39.4 \%)$ & $196(47.3 \%)$ & \\
\hline 1.75 & $15(17.2 \%)$ & $53(29.4 \%)$ & $88(21.3 \%)$ & \\
\hline 2 & $4(4.6 \%)$ & $9(5.0 \%)$ & $26(6.3 \%)$ & \\
\hline 2.25 & $1(1.1 \%)$ & $0(0.0 \%)$ & $1(0.2 \%)$ & \\
\hline More than 1 burr & $13(14.8 \%)$ & $23(12.5 \%)$ & $73(17.5 \%)$ & 0.289 \\
\hline Burr/artery ratio & $0.49 \pm 0.11$ & $0.50 \pm 0.09$ & $0.51 \pm 0.10$ & 0.292 \\
\hline Number of implanted stents & $1.85 \pm 1.3$ & $1.77 \pm 0.10$ & $1.92 \pm 0.98$ & 0.278 \\
\hline Stent diameter & $3.0 \pm 0.54$ & $3.1 \pm 0.47$ & $3.0 \pm 0.49$ & 0.429 \\
\hline Total stent length per lesion & $24[18-40]$ & $30[18-46]$ & $32[22-48]$ & 0.131 \\
\hline Post dilatation & $59(67.0 \%)$ & $115(62.8 \%)$ & $260(63.6 \%)$ & 0.787 \\
\hline Maximum post-dilatation balloon size & $3.5 \pm 0.5$ & $3.5 \pm 0.6$ & $3.4 \pm 0.5$ & 0.485 \\
\hline \multicolumn{5}{|l|}{ Type of stent } \\
\hline BMS & $3(3.4 \%)$ & $21(11.4 \%)$ & $28(6.7 \%)$ & 0.036 \\
\hline Early generation DES & $28(31.5 \%)$ & $83(45.1 \%)$ & $173(41.2 \%)$ & 0.098 \\
\hline New-generation DES & $56(62.9 \%)$ & $79(42.9 \%)$ & $226(53.8 \%)$ & 0.004 \\
\hline Glycoprotein IIb/IIIa inhibitor usage & $0(0.0 \%)$ & $4(2.2 \%)$ & $11(2.6 \%)$ & 0.309 \\
\hline $\begin{array}{l}\text { Percutaneous hemodynamic assist } \\
\text { devices }\end{array}$ & $7(7.9 \%)$ & $1(0.5 \%)$ & $2(0.5 \%)$ & $<0.001$ \\
\hline Impella & 2 & 0 & 1 & \\
\hline
\end{tabular}


Table 2 continued

\begin{tabular}{llll}
\hline & $\begin{array}{l}\text { LVEF } \leq 35 \%, \\
(\boldsymbol{n}=\mathbf{8 9} \text { lesions })\end{array}$ & $\begin{array}{l}\text { LVEF 36-54\%, } \\
(\boldsymbol{n}=\mathbf{1 8 4} \text { lesions })\end{array}$ & $\begin{array}{l}\text { LVEF } \geq 55 \%, \\
(\boldsymbol{n}=421 \text { lesions })\end{array}$ \\
\hline IABP & 4 & 1 & 1 \\
Impella and IABP & 1 & 0 & 0 \\
$\begin{array}{l}\text { Elective usage of percutaneous } \\
\text { hemodynamic assist devices }\end{array}$ & $5(6.1 \%)$ & $1(0.6 \%)$ & $0(0 \%)$ \\
$\begin{array}{l}\text { Procedural duration (min) } \\
\text { Amount of contrast material }\end{array}$ & $82[54-109]$ & $68[49-94]$ & $72[53-98]$ \\
\hline
\end{tabular}

Data are shown as number (percentage), median [interquartile range], mean \pm standard deviation $P C I$ percutaneous coronary intervention, ${ }^{*} B 2 / C$ according to ACC/AHA classification, $B M S$ bare metal stent, $D E S$ drugeluting stent, $I A B P$ intra aortic balloon pump

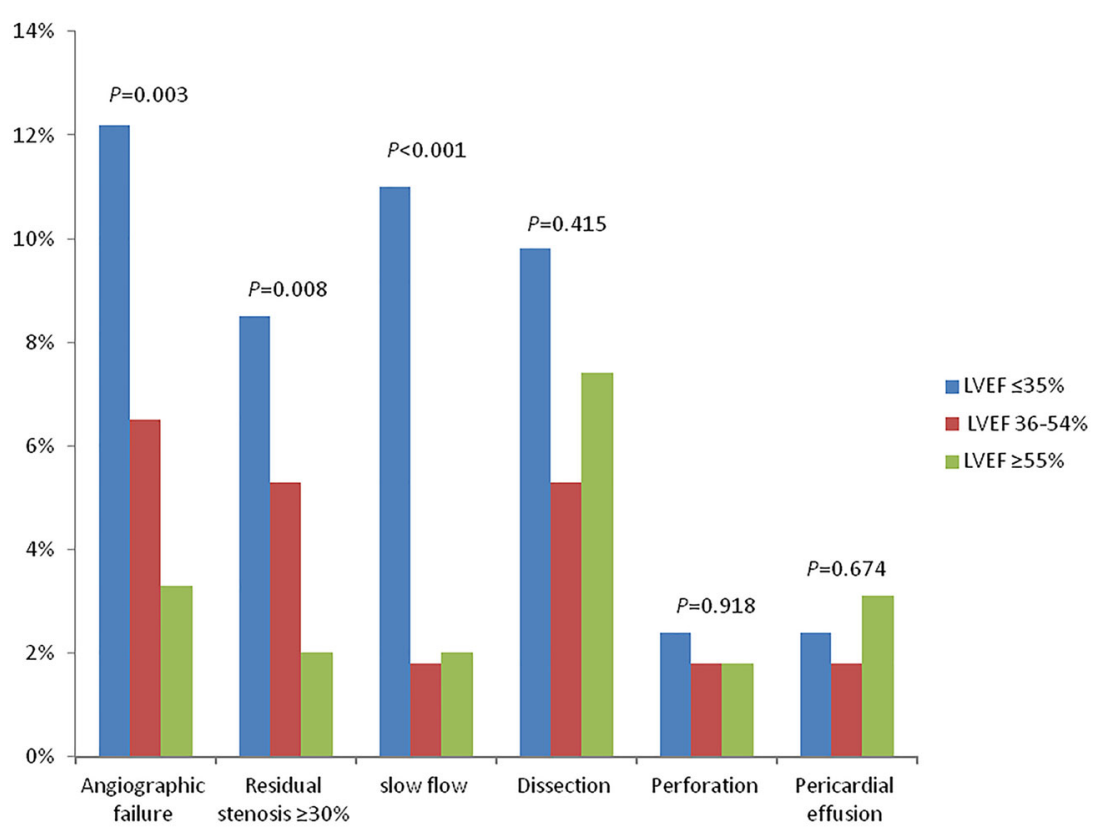

Fig. 2 Procedural outcomes. $L V E F$ left ventricular ejection fraction

95\% CI 1.24-14.03, $p=0.021$ ) with a trend towards higher mortality $(2.4$ vs. $0.5 \%$, $p=0.082)$. On the other hand, patients with moderately impaired LVEF did not show increased rates of in-hospital MACE $(p=0.405)$ in comparison to patients with preserved LVEF. The incidence of in-hospital MACE and its components is displayed in Fig. 3. On multivariate analysis, severely reduced LVEF was the only independent risk factor for in-hospital MACE (OR: 4.39, 95\% CI 1.63-11.81, $p=0.003$ ) (Table 4). 
Table 3 Independent predictors of angiographic failure

\begin{tabular}{|c|c|c|c|c|c|c|}
\hline & \multicolumn{3}{|c|}{ Univariate } & \multicolumn{3}{|c|}{ Multivariate } \\
\hline & $\begin{array}{l}\text { Odds } \\
\text { ratio }\end{array}$ & $\begin{array}{l}95 \% \text { confidence } \\
\text { interval }\end{array}$ & $\overline{p \text { value }}$ & $\begin{array}{l}\text { Odds } \\
\text { ratio }\end{array}$ & $\begin{array}{l}\text { 95\% confidence } \\
\text { interval }\end{array}$ & $p$ value \\
\hline $\mathrm{LVEF} \leq 35 \%$ & 4.05 & $1.71-9.59$ & 0.001 & 3.36 & $1.23-9.22$ & 0.018 \\
\hline LVEF $36-54 \%$ & 2.017 & $0.89-4.60$ & 0.095 & 1.86 & $0.71-4.85$ & 0.205 \\
\hline Chronic renal impairment & 0.85 & $0.32-2.25$ & 0.744 & & & \\
\hline $\begin{array}{l}\text { Two-vessel coronary artery } \\
\text { disease }\end{array}$ & 2.94 & $0.68-12.74$ & 0.150 & & & \\
\hline $\begin{array}{l}\text { Three-vessel coronary artery } \\
\text { disease }\end{array}$ & 3.42 & $0.75-15.6$ & 0.112 & & & \\
\hline Previous MI & 1.60 & $0.75-3.41$ & 0.227 & & & \\
\hline Previous PCI & 2.09 & $1.05-4.17$ & 0.036 & 1.35 & $0.59-3.08$ & 0.474 \\
\hline Previous CABG & 1.341 & $0.61-2.93$ & 0.463 & & & \\
\hline \multicolumn{7}{|l|}{ Target vessel } \\
\hline Left main & 0.38 & $0.09-1.62$ & 0.192 & & & \\
\hline Left anterior descending & 1.05 & $0.53-2.08$ & 0.884 & & & \\
\hline Left circumflex & 1.50 & $0.69-3.29$ & 0.310 & & & \\
\hline Chronic total occlusion & 2.82 & $1.11-7.17$ & 0.030 & 2.96 & $1.04-8.46$ & 0.043 \\
\hline Ostial lesion & 0.48 & $0.18-1.25$ & 0.132 & & & \\
\hline New-generation DES & 2.24 & $0.93-5.42$ & 0.073 & 1.96 & $0.79-4.84$ & 0.146 \\
\hline
\end{tabular}

$M I$ myocardial infarction, $P C I$ percutaneous coronary intervention, $C A B G$ coronary artery bypass grafting, $D E S$ drugeluting stent

\section{Evolution of Procedural Outcomes and In- Hospital MACE over the Study Period}

In order to investigate the effect of the time factor over the rates of procedural outcomes, patients were divided chronologically into four quartiles according to the timing of the indexed procedures. No significant difference was found between different periods in term of the rates of procedural outcomes as well as in-hospital MACE (Supplementary Table 2).

The distribution of baseline characteristics over the time quartiles are shown in Supplementary Table 1 .

\section{MACE at Five Years}

The rate of MACE at 5 years was higher in patients with severely reduced LVEF, driven by a higher rate of all-cause death. There was no significant difference across the LVEF groups regarding the rates of MI and TVR (Fig. 4). On multivariate analysis, MACE was no longer significantly associated with severely reduced LVEF (HR: 1.26, 95\% CI 0.80-1.99, $p=0.310$ ) but rather with chronic renal impairment (HR: 1.50, 95\% CI 1.01-2.23, $p=0.045)$ left anterior descending (LAD) artery as the target vessel during the index procedure (HR: $0.68,95 \% \mathrm{CI}$ $0.48-0.95, p=0.025$ ) (Table 5). On the other hand, severely reduced LVEF (HR: 2.57, 95\% CI 


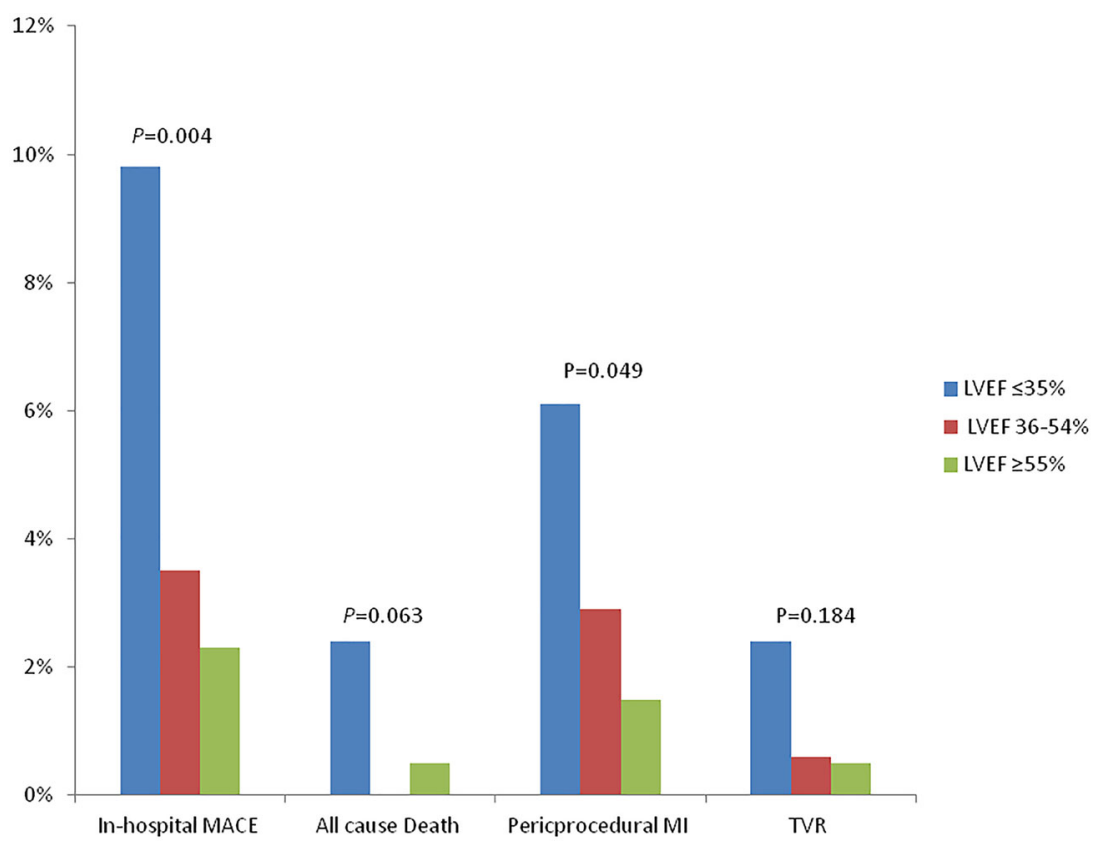

Fig. 3 In-hospital MACE. MACE major adverse cardiac events, $M I$ myocardial infarction, TVR target vessel revascularization, $L V E F$ left ventricular ejection fraction

$1.38-4.79, p=0.003$ ) as well as in moderately reduced LVEF patients (HR: 1.95, 95\% CI 1.15-3.29, $p=0.013$ ) and chronic renal impairment (HR: 3.53, 95\% CI 2.13-5.82, $p<0.001)$ remained independent predictors of all-cause death (Table 6).

\section{DISCUSSION}

The principal findings of this analysis are as follows:

1. RA is safe in patients with moderately impaired LV function but is associated with acute hazards in patients with severely depressed LV function.

2. On the long term, LV function has its wellknown effect on mortality with a gradual increase in mortality rates with decreasing LVEF.

3. LV function does not affect TVR rates on the long term after RA

Although LV dysfunction is seen in 10-30\% of patients undergoing PCI, patients with impaired LVEF are mostly excluded from contemporary PCI trials $[14,15]$. Although recent
ESC practice guidelines recommend revascularization in heart failure patients (LVEF $<35 \%)$ with suitable coronary anatomy, this is mainly concluded from the CABG trial [16]. Therefore, the optimal management and the outcomes of patients with impaired LV function still represent a scientific gap in the setting of complex PCIs.

Data on RA in patients with impaired LV function are scarce, but indicate a higher incidence of adverse events in this patient population. In a recent study by McEntegart et al., RA was associated with a type $4 \mathrm{a}$ MI rate of $24 \%$ as detected by cardiac magnetic resonance (CMR). Moreover, CMR demonstrated myocardial injury in more than half of the patients, and this injury persisted beyond 6 months in $14 \%$ of them [17]. Indeed, this is a much higher rate than in our analysis, with a total incidence of peri-procedural MI of $2.5 \%$, but one should consider the usage of the CMR with its high sensitivity and specificity for MI detection in combination with troponin increase. In two other recent studies by Watanabe et al. [18] and Whiteside et al. [19], slow flow was significantly higher in severely reduced LVEF patients 
Table 4 Independent predictors of in-hospital MACE

\begin{tabular}{|c|c|c|c|c|c|c|}
\hline & \multicolumn{3}{|c|}{ Univariate } & \multicolumn{3}{|c|}{ Multivariate } \\
\hline & $\begin{array}{l}\text { Odds } \\
\text { ratio }\end{array}$ & $\begin{array}{l}95 \% \text { confidence } \\
\text { interval }\end{array}$ & $\overline{p \text { value }}$ & $\begin{array}{l}\text { Odds } \\
\text { ratio }\end{array}$ & $\begin{array}{l}95 \% \text { confidence } \\
\text { interval }\end{array}$ & $p$ value \\
\hline $\mathrm{LVEF} \leq 35 \%$ & 4.60 & $1.72-12.31$ & 0.002 & 4.39 & $1.63-11.81$ & 0.003 \\
\hline LVEF $36-54 \%$ & 1.56 & $0.55-4.45$ & 0.408 & 1.45 & $0.50-4.17$ & 0.494 \\
\hline Chronic renal impairment & 1.09 & $0.36-3.26$ & 0.882 & & & \\
\hline $\begin{array}{l}\text { Two-vessel coronary artery } \\
\text { disease }\end{array}$ & 4.164 & $0.54-31.92$ & 0.170 & & & \\
\hline $\begin{array}{l}\text { Three-vessel coronary artery } \\
\text { disease }\end{array}$ & 3.92 & $0.48-32.33$ & 0.204 & & & \\
\hline Previous MI & 1.08 & $0.39-2.97$ & 0.880 & & & \\
\hline Previous PCI & 1.17 & $0.50-2.70$ & 0.722 & & & \\
\hline Previous CABG & 1.06 & $0.39-2.91$ & 0.910 & & & \\
\hline \multicolumn{7}{|l|}{ Target vessel } \\
\hline Left main & 0.30 & $0.04-2.17$ & 0.228 & & & \\
\hline Left anterior descending & 0.91 & $0.39-2.08$ & 0.814 & & & \\
\hline Left circumflex & 0.89 & $0.30-2.66$ & 0.831 & & & \\
\hline Chronic total occlusion & 2.79 & $0.91-8.54$ & 0.073 & 2.49 & $0.79-7.82$ & 0.119 \\
\hline Ostial lesion & 0.61 & $0.21-1.83$ & 0.380 & & & \\
\hline New-generation DES & 0.70 & $0.27-1.85$ & 0.476 & & & \\
\hline
\end{tabular}

$M I$ myocardial infarction, $P C I$ percutaneous coronary intervention, $C A B G$ coronary artery bypass grafting, $D E S$ drugeluting stent

[defined as $\leq 35 \%$ by Watanabe et al. $(n=33)$ and as $\leq 30 \%$ by Whiteside et al. $(n=18)]$.

In line with those studies, we also found that slow flow was more than five-fold higher in patients with severely reduced LVEF (as compared to preserved LVEF) in spite of excluding patients presenting with myocardial infarction from the analysis. These data collectively confirm a strong relationship between LVEF impairment and the risk of slow flow after RA. Previous studies have indeed indicated that coronary flow is closely related to both systolic and diastolic LV function and that slow coronary flow is more frequent in patients with $\mathrm{LV}$ dysfunction $[20,21]$. It is worth noting that the operators in our study did not react with glycoprotein IIb/IIIa inhibitors to slow-flow events possibly because of concomitant higher bleeding risks in the cohort with bad ventricular function.

In general, PCI in patients with LVEF $<35 \%$ is associated with higher in-hospital mortality rates $[22,23]$ and is considered as a high-risk PCI $[10,24]$. According to the ACCF/AHA/SCAI guidelines for PCI, PMCS is recommended in high-risk PCIs including PCIs in patients with < LVEF 35\% [10]. Although not specifically addressed by contemporary practice guidelines, hemodynamic support would theoretically convey an even extra benefit in patients with reduced EF undergoing RA, where the hemodynamic consequences of 

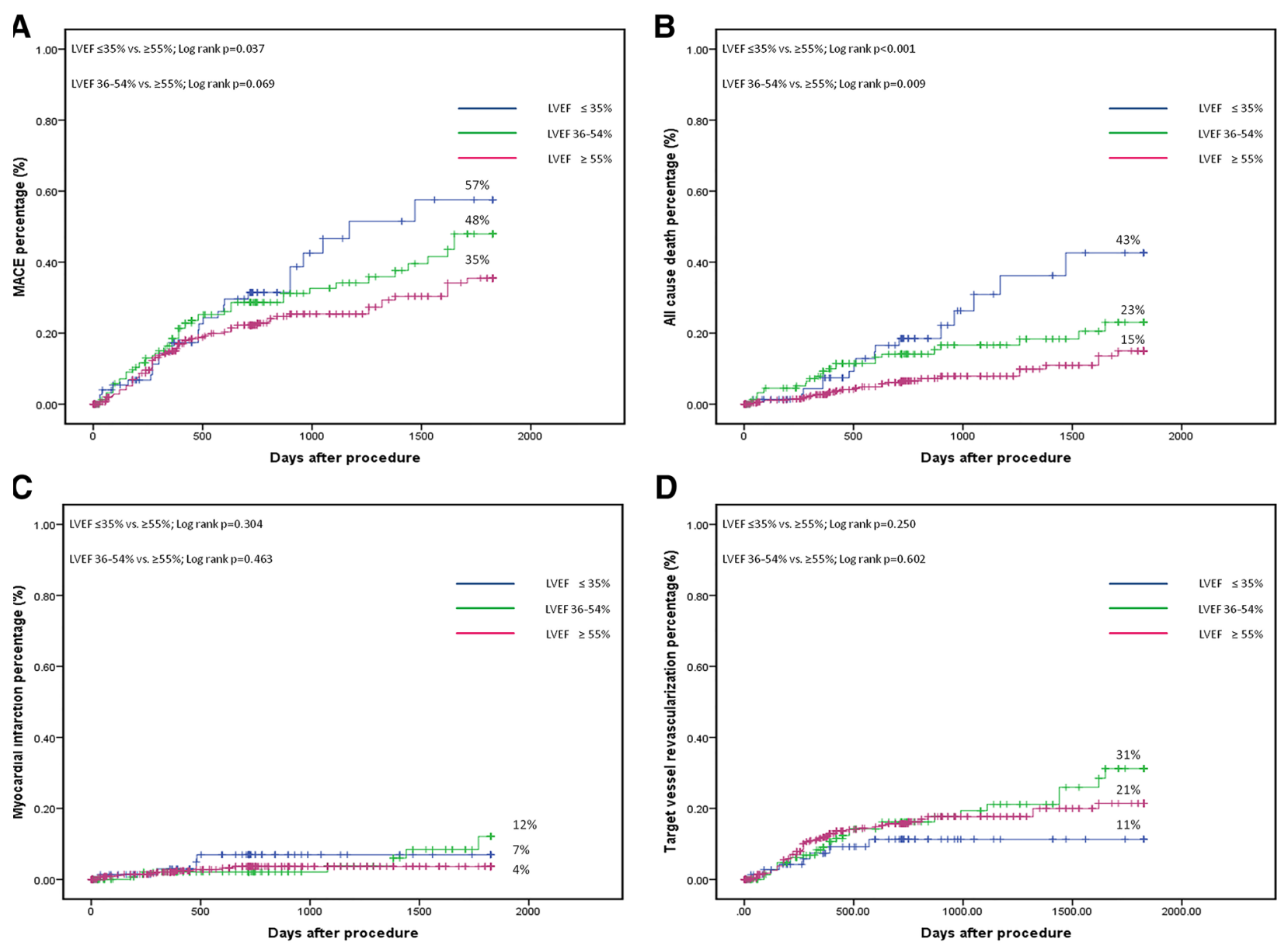

Fig. 4 a Kaplan-Meier curve for the cumulative incidence of MACE. b Kaplan-Meier curve for the cumulative incidence of all cause death. c Kaplan-Meier curve for the

cumulative incidence of MI. d Kaplan-Meier curve for the cumulative incidence of TVR

intervention are more profound than in standard PCIs. In our study, PMCS was more frequently used in the severely reduced LVEF group in a total of seven cases, but this relatively small number of patients precluded further valid statistical comparisons.

We observed that there was an association between LV function impairment and higher rates of residual stenosis $\geq 30 \%$. Unlike in general PCI populations where excellent angiographic results can still be achieved in patients with reduced LVEF $[25,26]$, it appears that such favorable procedural outcome is less frequent in the setting of very complex lesions requiring RA. A possible explanation for this observation is that a suboptimal angiographic result is more likely accepted in this group of patients.

Notably, although the acute angiographic results were suboptimal in patients with reduced LVEF, this did not translate to higher rates of TVR in the long term.

As rotational and orbital atherectomy provide comparable clinical outcomes at shortterm follow-up [27], we find it useful to compare our results with the outcomes of the ORBIT II study [28]. In contrast to our study, there was no significant difference in the rate of angiographic failure, procedural outcomes, or inhospital MACE between the reduced LVEF groups $(\mathrm{LVEF}=26-40 \%$ and $\mathrm{LVEF}=41-50 \%)$ and preserved LVEF patients (LVEF $>50 \%$ ) in the ORBIT II. These results should be interpreted with the knowledge that severe tortuous coronary vessels were excluded from the ORBIT 
Table 5 Independent predictors of 5-year MACE

\begin{tabular}{|c|c|c|c|c|c|c|}
\hline & \multicolumn{3}{|c|}{ Univariate } & \multicolumn{3}{|c|}{ Multivariate } \\
\hline & $\begin{array}{l}\text { Hazard } \\
\text { ratio }\end{array}$ & $\begin{array}{l}95 \% \text { confidence } \\
\text { interval }\end{array}$ & $p$ value & $\begin{array}{l}\text { Hazard } \\
\text { ratio }\end{array}$ & $\begin{array}{l}95 \% \text { confidence } \\
\text { interval }\end{array}$ & $p$ value \\
\hline $\mathrm{LVEF} \leq 35 \%$ & 1.56 & $1.01-2.42$ & 0.047 & 1.26 & $0.80-1.99$ & 0.310 \\
\hline LVEF $36-54 \%$ & 1.42 & $1.02-1.97$ & 0.040 & 1.21 & $0.86-1.71$ & 0.279 \\
\hline Chronic renal impairment & 1.57 & $1.06-2.31$ & 0.023 & 1.50 & $1.01-2.23$ & 0.045 \\
\hline $\begin{array}{l}\text { Two-vessel coronary artery } \\
\text { disease }\end{array}$ & 1.15 & $0.74-1.78$ & 0.534 & & & \\
\hline $\begin{array}{l}\text { Three-vessel coronary artery } \\
\text { disease }\end{array}$ & 1.04 & $0.64-1.70$ & 0.866 & & & \\
\hline Previous MI & 1.28 & $0.91-1.79$ & 0.151 & & & \\
\hline Previous PCI & 0.947 & $0.70-1.29$ & 0.727 & & & \\
\hline Previous CABG & 1.24 & $0.87-1.75$ & 0.225 & & & \\
\hline \multicolumn{7}{|l|}{ Target vessel } \\
\hline Left main & 0.92 & $0.59-1.43$ & 0.696 & & & \\
\hline Left anterior descending & 0.61 & $0.45-0.83$ & 0.001 & 0.68 & $0.48-0.95$ & 0.025 \\
\hline Left circumflex & 1.45 & $1.02-2.05$ & 0.039 & 1.08 & $0.72-1.64$ & 0.699 \\
\hline Chronic total occlusion & 1.19 & $0.66-2.14$ & 0.563 & & & \\
\hline Ostial lesion & 1.56 & $1.14-2.13$ & 0.006 & 1.26 & $0.90-1.78$ & 0.183 \\
\hline New-generation DES & 0.78 & $0.56-1.10$ & 0.159 & & & \\
\hline
\end{tabular}

$M I$ myocardial infarction, $P C I$ percutaneous coronary intervention, $C A B G$ coronary artery bypass grafting, $D E S$ drugeluting stent

II as well as patients with LVEF $\leq 25 \%$, and that a residual stenosis of less than $50 \%$ was considered acceptable. Whether orbital atherectomy is associated with less cardio-depression and microcirculation disturbance in the setting of impaired LV function is unknown, and insights into these questions from ORACLE trial (NCT03021577) are awaited.

In an analysis of more than 230,000 PCI procedures, worsening LVEF independently predicted long-term mortality outcomes [29]. Moreover, the Dynamic Registry investigators observed similar results with reduced LVEF as a predictor of long-term mortality with no significant differences regarding long-term TVR across different LVEF groups [23]. In line with these observations in global PCI settings, our analysis showed a stepwise increase in 5-year mortality with decreasing LVEF as well as no association between LVEF and TVR. In the same manner, the rate of 1 -year cardiac death in ORBIT II study increased as LVEF decreased, while the rate of 1-year TVR was comparable across the LVEF groups. These observations from our series as well as from the ORBIT II indicate that, as in other PCI settings, the longterm survival after RA mainly depends on LV function.

Lastly, considering the long follow-up period of this study. The rates of procedural outcomes as well as in-hospital MACE were equally 
Table 6 Independent predictors of 5-year all-cause death

\begin{tabular}{|c|c|c|c|c|c|c|}
\hline & \multicolumn{3}{|c|}{ Univariate } & \multicolumn{3}{|c|}{ Multivariate } \\
\hline & $\begin{array}{l}\text { Hazard } \\
\text { ratio }\end{array}$ & $\begin{array}{l}95 \% \text { confidence } \\
\text { interval }\end{array}$ & $\overline{p \text { value }}$ & $\begin{array}{l}\text { Hazard } \\
\text { ratio }\end{array}$ & $\begin{array}{l}\text { 95\% confidence } \\
\text { interval }\end{array}$ & $\overline{p \text { value }}$ \\
\hline LVEF $\leq 35 \%$ & 3.08 & $1.67-5.67$ & $<0.001$ & 2.57 & $1.38-4.79$ & 0.003 \\
\hline LVEF $36-54 \%$ & 2.19 & $1.31-3.66$ & 0.003 & 1.95 & $1.15-3.29$ & 0.013 \\
\hline Chronic renal impairment & 3.84 & $2.36-6.27$ & $<0.001$ & 3.53 & $2.13-5.82$ & $<0.001$ \\
\hline $\begin{array}{l}\text { Two-vessel coronary artery } \\
\text { disease }\end{array}$ & 1.32 & $0.67-2.60$ & 0.430 & & & \\
\hline $\begin{array}{l}\text { Three-vessel coronary artery } \\
\text { disease }\end{array}$ & 0.92 & $0.42-2.01$ & 0.838 & & & \\
\hline Previous MI & 0.96 & $0.56-1.65$ & 0.881 & & & \\
\hline Previous PCI & 0.68 & $0.42-1.11$ & 0.121 & & & \\
\hline Previous CABG & 0.88 & $0.50-1.56$ & 0.667 & & & \\
\hline \multicolumn{7}{|l|}{ Target vessel } \\
\hline Left main & 0.84 & $0.42-1.69$ & 0.623 & & & \\
\hline Left anterior descending & 0.78 & $0.50-1.22$ & 0.272 & & & \\
\hline Left circumflex & 1.18 & $0.68-2.04$ & 0.563 & & & \\
\hline Chronic total occlusion & 1.142 & $0.46-2.83$ & 0.774 & & & \\
\hline Ostial lesion & 1.34 & $0.83-2.17$ & 0.236 & & & \\
\hline New-generation DES & 0.94 & $0.56-1.58$ & 0.821 & & & \\
\hline
\end{tabular}

$M I$ myocardial infarction, $P C I$ percutaneous coronary intervention, $C A B G$ coronary artery bypass grafting, $D E S$ drugeluting stent, $M A C E$ major adverse cardiac events, $M I$ myocardial infarction, $T V R$ target vessel revascularization, $L V E F$ left ventricular ejection fraction

distributed among the course of time in our cohort.

Inspite of aging of the population as well as increasing rates of chronic renal impairment and repeated PCI over time course, our periprocedural outcomes did not worsen over time. That in turn emphasis the evolution in usage of RA in our cohort as the operators became more proficient as time passes.

\section{Limitations}

First, this is a single-center retrospective study. Second, although this is the largest study to date investigating RA outcomes in patients with reduced LVEF, numbers of adverse events remain relatively small.

\section{CONCLUSIONS}

Patients with severely reduced LVEF $(\leq 35 \%)$ undergoing RA had higher rates of angiographic failure (driven by higher residual stenosis and slow flow) and in-hospital MACE (driven by higher peri-procedural MI). Long term, there was a stepwise increase in all-cause mortality with decreasing LVEF, while the reduction of LVEF was not associated with increased TVR rates. 


\section{ACKNOWLEDGEMENTS}

Funding. No funding or sponsorship was received for this study or publication of this article.

Authorship. All named authors meet the International Committee of Medical Journal Editors (ICMJE) criteria for authorship for this article, take responsibility for the integrity of the work as a whole, and have given their approval for this version to be published.

Prior Presentation. The data presented in this study were presented as an abstract in EURO PCR 2019.

Disclosures. Gert Richardt has received institutional research grants from St. Jude Medical, Biotronik, and Medtronic and is a member of the journal's Editorial Board. Mohamed Abdel-Wahab is a proctor for Boston Scientific and a consultant to Medtronic and Edwards Lifesciences. Nader Mankerious, Rayyan Hemetsberger, Ralph Toelg, and Abdelhakim Allali have nothing to disclose.

Compliance with Ethics Guidelines. Written informed consent was obtained from all patients for analysis of their anonymized data, and data collection was approved by the local ethics committee (Segeberger kliniken Gmbh, Bad Segeberg, Germany). The study conforms to the Helsinki Declaration of 1964, as revised in 2013, concerning human and animal rights

Data Availability. The datasets analyzed during the current study are available from the corresponding author on reasonable request.

Open Access. This article is distributed under the terms of the Creative Commons Attribution-NonCommercial 4.0 International License (http://creativecommons.org/licenses/ by-nc/4.0/), which permits any noncommercial use, distribution, and reproduction in any medium, provided you give appropriate credit to the original author(s) and the source, provide a link to the Creative Commons license, and indicate if changes were made.

\section{REFERENCES}

1. Barbato E, Carrie D, Dardas P, Fajadet J, Gaul G, Haude $M$, et al. European expert consensus on rotational atherectomy. EuroIntervention. 2015;11(1):30-6.

2. Genereux P, Madhavan MV, Mintz GS, Maehara A, Palmerini $\mathrm{T}$, Lasalle $\mathrm{L}$, et al. Ischemic outcomes after coronary intervention of calcified vessels in acute coronary syndromes. Pooled analysis from the HORIZONS-AMI (Harmonizing Outcomes With Revascularization and Stents in Acute Myocardial Infarction) and ACUITY (Acute Catheterization and Urgent Intervention Triage Strategy) TRIALS. J Am Coll Cardiol. 2014;63(18):1845-54.

3. Bourantas CV, Zhang YJ, Garg S, Iqbal J, Valgimigli $\mathrm{M}$, Windecker $\mathrm{S}$, et al. Prognostic implications of coronary calcification in patients with obstructive coronary artery disease treated by percutaneous coronary intervention: a patient-level pooled analysis of 7 contemporary stent trials. Heart. 2014;100(15):1158-64.

4. Abdel-Wahab M, Richardt G, Joachim Buttner $H$, Toelg R, Geist V, Meinertz T, et al. High-speed rotational atherectomy before paclitaxel-eluting stent implantation in complex calcified coronary lesions: the randomized ROTAXUS (Rotational Atherectomy Prior to Taxus Stent Treatment for Complex Native Coronary Artery Disease) trial. JACC Cardiovasc Interv. 2013;6(1):10-9.

5. Lee MS, Yang T, Lasala J, Cox D. Impact of coronary artery calcification in percutaneous coronary intervention with paclitaxel-eluting stents: two-year clinical outcomes of paclitaxel-eluting stents in patients from the ARRIVE program. Catheter Cardiovasc Interv. 2016;88(6):891-7.

6. Devereux RB, Roman MJ, Paranicas M, Lee ET, Welty TK, Fabsitz RR, et al. A population-based assessment of left ventricular systolic dysfunction in middle-aged and older adults: the Strong Heart Study. Am Heart J. 2001;141(3):439-46.

7. Kaneko H, Yajima J, Oikawa Y, Tanaka S, Fukamachi D, Suzuki S, et al. Impact of aging on the clinical outcomes of Japanese patients with coronary artery disease after percutaneous coronary intervention. Heart Vessels. 2014;29(2):156-64.

8. Ahn SS, Auth D, Marcus DR, Moore WS. Removal of focal atheromatous lesions by angioscopically 
guided high-speed rotary atherectomy. Preliminary experimental observations. J Vasc Surg. 1988;7(2):292-300.

9. Abdel-Wahab M, Toelg R, Byrne RA, Geist V, ElMawardy M, Allali A, et al. High-speed rotational atherectomy versus modified balloons prior to drug-eluting stent implantation in severely calcified coronary lesions. Circ Cardiovasc Interv. 2018;11(10):e007415.

10. Levine GN, Bates ER, Blankenship JC, Bailey SR, Bittl JA, Cercek B, et al. 2011 ACCF/AHA/SCAI Guideline for Percutaneous Coronary Intervention. A report of the American College of Cardiology Foundation/American Heart Association Task Force on Practice Guidelines and the Society for Cardiovascular Angiography and Interventions. J Am Coll Cardiol. 2011;58(24):e44-122.

11. Lang RM, Badano LP, Mor-Avi V, Afilalo J, Armstrong A, Ernande L, et al. Recommendations for cardiac chamber quantification by echocardiography in adults: an update from the American Society of Echocardiography and the European Association of Cardiovascular Imaging. Eur Heart J Cardiovasc Imaging. 2015;16(3):233-70.

12. Allali A, Abdel-Wahab M, Sulimov DS, Jose J, Geist V, Kassner $G$, et al. Comparison of bailout and planned rotational atherectomy for heavily calcified coronary lesions: a single-center experience. J Interv Cardiol. 2017;30(2):124-33.

13. Thygesen K, Alpert JS, Jaffe AS, Simoons ML, Chaitman BR, White HD, et al. Third universal definition of myocardial infarction. J Am Coll Cardiol. 2012;60(16):1581-98.

14. Grayson AD, Moore RK, Jackson M, Rathore S, Sastry S, Gray TP, et al. Multivariate prediction of major adverse cardiac events after 9914 percutaneous coronary interventions in the north west of England. Heart. 2006;92(5):658-63.

15. Boden WE, O'Rourke RA, Teo KK, Hartigan PM, Maron DJ, Kostuk W, et al. Design and rationale of the clinical outcomes utilizing revascularization and aggressive DruG evaluation (COURAGE) trial veterans affairs cooperative studies Program no. 424. Am Heart J. 2006;151(6):1173-9.

16. Velazquez EJ, Lee KL, Jones RH, Al-Khalidi HR, Hill JA, Panza JA, et al. Coronary-artery bypass surgery in patients with ischemic cardiomyopathy. N Engl J Med. 2016;374(16):1511-20.

17. McEntegart M, Corcoran D, Carrick D, Clerfond G, Sidik N, Collison D, et al. Incidence of procedural myocardial infarction and cardiac magnetic resonance imaging-detected myocardial injury following percutaneous coronary intervention with rotational atherectomy. EuroIntervention. 2018;14(7):819-23.

18. Watanabe $Y$, Naganuma $T$, Kawamoto $H$, Ishiguro $\mathrm{H}$, Nakamura S. In-hospital outcomes after rotational atherectomy in patients with low ejection fraction. Scand Cardiovasc J. 2018;52(4):177-82.

19. Whiteside HL, Ratanapo S, Nagabandi A, Kapoor D. Outcomes of rotational atherectomy in patients with severe left ventricular dysfunction without hemodynamic support. Cardiovasc Revasc Med. 2018;19(6):660-5.

20. Li Y, Wang Y, Jia D, Lv Y, Zhang Y, Guan Z, et al. Assessment of risk factors and left ventricular function in patients with slow coronary flow. Heart Vessels. 2016;31(3):288-97.

21. Nurkalem Z, Gorgulu S, Uslu N, Orhan AL, Alper AT, Erer $B$, et al. Longitudinal left ventricular systolic function is impaired in patients with coronary slow flow. Int J Cardiovasc Imaging. 2009;25(1):25-32.

22. Wallace TW, Berger JS, Wang A, Velazquez EJ, Brown DL. Impact of left ventricular dysfunction on hospital mortality among patients undergoing elective percutaneous coronary intervention. Am J Cardiol. 2009;103(3):355-60.

23. Keelan PC, Johnston JM, Koru-Sengul T, Detre KM, Williams DO, Slater J, et al. Comparison of in-hospital and one-year outcomes in patients with left ventricular ejection fractions $<$ or $=40 \%, 41 \%$ to $49 \%$, and $>$ or $=50 \%$ having percutaneous coronary revascularization. Am J Cardiol. 2003;91(10):1168-72.

24. O'Neill WW, Kleiman NS, Moses J, Henriques JP, Dixon S, Massaro J, et al. A prospective, randomized clinical trial of hemodynamic support with Impella 2.5 versus intra-aortic balloon pump in patients undergoing high-risk percutaneous coronary intervention: the PROTECT II study. Circulation. 2012;126(14):1717-27.

25. Sheiban I, Moretti C, Biondi Zoccai G, Rosano GM, Sciuto F, Grosso Marra W, et al. Short- and longterm outcomes of percutaneous coronary interventions in patients with severe left ventricular dysfunction. EuroIntervention. 2007;3(3):359-64.

26. Alidoosti M, Salarifar M, Zeinali AM, Kassaian SE, Dehkordi MR, Fatollahi MS. Short- and long-term outcomes of percutaneous coronary intervention in patients with low, intermediate and high ejection fraction. Cardiovasc J Afr. 2008;19(1):17-21.

27. Lee MS, Park KW, Shlofmitz E, Shlofmitz RA. Comparison of rotational atherectomy versus orbital atherectomy for the treatment of heavily calcified coronary plaques. Am J Cardiol. 2017;119(9):1320-3. 
28. Lee MS, Martinsen BJ, Shlofmitz R, Shlofmitz E, Lee AC, Chambers J. Orbital atherectomy treatment of severely calcified coronary lesions in patients with impaired left ventricular ejection fraction: one-year outcomes from the ORBIT II study. EuroIntervention. 2017;13(3):329-37.
29. Mamas MA, Anderson SG, O'Kane PD, Keavney B, Nolan J, Oldroyd KG, et al. Impact of left ventricular function in relation to procedural outcomes following percutaneous coronary intervention: insights from the British Cardiovascular Intervention Society. Eur Heart J. 2014;35(43):3004-12a. 